\title{
Methodological approaches to assessing the technical and economic efficiency of the building materials and structures' use
}

\author{
Inna Akulova*, Galina Slavcheva, and Dmitry Simonov \\ Voronezh State Technical University, 394006, Voronezh, Russia
}

\begin{abstract}
The technical and economic efficiency actual problem of the use of building materials, products and structures is considered. Taking into account the purpose, a grouping of building materials was carried out according to eight nomenclature groups of structural, structural and heatinsulating, heat-insulating, acoustic, finishing, waterproofing and roofing materials, as well as the materials for special and general purposes. It is proposed to assess the technical and economic efficiency of building materials that form various nomenclature groups on the basis of two methodological approaches. The first approach should be applied to the building materials with one pronounced functional property, and the second - for the materials with several properties, the priority of which is not obvious. The calculations are carried out according to the criterion of the maximum units of useful effect due to the use of materials per unit of associated costs. In the second case, it is advisable to use the expert assessments to determine the significance of functional properties. Methodical recommendations for the technology of their implementation are provided.
\end{abstract}

\section{Introduction}

Assessment of technical and economic efficiency is a key issue in solving the problem of using building materials, products and structures in construction practice.

In the most general understanding, the effectiveness of any product is determined by the ratio of the result and the costs required to obtain it. Taking into account this provision, the determination of technical and economic efficiency is carried out in the process of correlating the technical parameters of the product, reflecting its functional properties, and the costs expressed in monetary form for its receipt or acquisition. Thus, the criterion of technical and economic efficiency is the maximum units of useful effect per unit of costs incurred [1 - 9].

In relation to building materials, products and structures, the development of a unified methodological approach to assessing the technical and economic efficiency of their application is, in our opinion, very problematic due to the presence of a large number of significantly different functional properties. Such a variety of properties requires the

* Corresponding author: akulovaii@yandex.ru 
identification of a number of nomenclature groups of building materials, within which it is possible to apply a single scheme for calculating their technical and economic efficiency.

It should be noted that the nomenclature group is understood as a set of types of building materials, combined according to the characteristics of purpose and identity of functional properties.

Taking into account the above-said, the following nomenclature groups of building materials, products and structures are highlighted:

1) structural - receiving and transmitting loads;

2) structural and thermal insulation - combining the functions of the building interior loads and thermal protection perception;

3) heat-insulating - ensuring the building thermal regime;

4) acoustic - with sound-absorbing and sound-insulating properties;

5) waterproofing and roofing - creating waterproof layers on roofs and other building structures;

6) finishing - used to improve the decorative qualities of building structures, as well as to protect them from external influences;

7) special-purpose materials - used in special structures (refractory, heat-resistant, acidresistant materials, etc.)

8) general-purpose materials - cement, lime, aggregates, etc.

\section{Results and Discussion}

Based on the generalization and analysis of the requirements for the selected nomenclature groups' use features in construction practice, to assess technical and economic efficiency of the building materials and products included in their composition, it is recommended to use two methodological approaches based on the criteria for the maximum units of useful effect per unit of costs incurred.

The first approach: it is advisable to apply to building materials and products with one obviously main functional property. This is typical for groups of structural, heat-insulating, acoustic, waterproofing and roofing materials, as well as the special-purpose materials [10 14]. It is proposed to evaluate the technical and economic efficiency within these groups according to the general scheme

$$
\mathrm{TE}_{\mathrm{ij}}^{\mathrm{f}}=\frac{\mathrm{a}_{\mathrm{ij}}^{\mathrm{min}}}{\mathrm{C}_{\mathrm{ij}}}
$$

where $\mathrm{a}_{\mathrm{ij}}^{\min }$ - is the lower normative limit of the main property of the $\mathrm{i}$-th building material included in the $\mathrm{j}$-th nomenclature group, nat. unit; $\mathrm{C}_{\mathrm{ij}}$ - is the cost of purchasing a unit of the $\mathrm{i}$-th building material included in the $\mathrm{j}$-th nomenclature group, $\mathrm{c}$.

We concretize the calculation schemes by the item groups:

- group of construction materials (performance-determining strength)

$$
\mathrm{TE}_{\mathrm{s}}^{\mathrm{f}}=\frac{\mathrm{R}_{\mathrm{bi}}}{\overline{\mathrm{C}_{\mathrm{s} 1}}}
$$

where $\mathrm{R}_{\mathrm{b}}$ - is the lower standard compressive strength of the $\mathrm{i}$-th structural material, MPa;

$\overline{\mathrm{C}_{\mathrm{sl}}}$ - is an average market price of the $\mathrm{i}$-th structural material, c./nat. unit.

- group of thermal insulation materials (main functional property thermal resistance)

$$
\mathrm{TE}_{\mathrm{ti}}^{\mathrm{f}}=\frac{\mathrm{R}_{\mathrm{ti}}}{\overline{\mathrm{C}_{\mathrm{t} 11}}}
$$


where $\mathrm{R}_{\mathrm{ti}}-$ is the thermal resistance of the $\mathrm{i}$-th heat-insulating material, $\left(\mathrm{m}^{2}{ }^{\circ} \mathrm{C}\right) / \mathrm{W}$;

$\overline{\mathrm{C}_{\mathrm{t} I l}}-$ is an average market price of the $\mathrm{i}$-th thermal insulation material, c./nat. unit.

- group of acoustic materials (the main property when choosing the type of material is sound insulating ability)

$$
\mathrm{TE}_{\mathrm{ac}}^{\mathrm{f}}=\frac{R_{w i}}{\overline{C_{a c l}}}
$$

where $R_{w i}$ - is a sound insulation index for airborne noise of the $i$-th acoustic material, $d B$; $\overline{\mathrm{C}_{\mathrm{acl}}}-$ is an average market price of the $\mathrm{i}$-th acoustic material, c./nat. unit.

- group of waterproofing and roofing materials (the most significant functional property is water resistance)

$$
\mathrm{TE}_{\mathrm{wp}}^{\mathrm{f}}=\frac{\mathrm{w}_{\mathrm{i}}}{\overline{\mathrm{C}_{\mathrm{wp} 1}}}
$$

where $\mathrm{W}_{\mathrm{i}}$ - is water resistance of the $\mathrm{i}$-th waterproofing or roofing material, $\mathrm{MPa}$;

$\overline{\mathrm{C}_{\mathrm{wpl}}}$ - is an average market price of the i-th waterproofing or roofing material, c./nat. unit.

- group of materials for special purposes (the main functional property is determined in accordance with the purpose)

$$
\mathrm{TE}_{\mathrm{sa}}^{\mathrm{f}}=\frac{\mathrm{L}_{\mathrm{qi}}}{\overline{\mathrm{C}_{\mathrm{sa}}}}
$$

where $\mathrm{L}_{\mathrm{q} i}$ - is the value of the q-th normative limit of the critical property (taking into account the purpose) of the i-th special-purpose material in the corresponding units of measurement;

$\overline{\mathrm{C}_{\mathrm{sal}}}$ - is an average market price of the $\mathrm{i}$-th special purpose material, c./nat. unit.

- general purpose material group (the main functional property is determined by the specifics of the material)

a) cement

$$
\mathrm{TE}_{\mathrm{ca}}^{\mathrm{f}}=\frac{\mathrm{R}_{\mathrm{b}}^{\mathrm{cem}}}{\overline{\mathrm{C}_{\mathrm{cem}}}}
$$

where $\mathrm{R}_{\mathrm{b}}^{\text {cem }}-$ is an ultimate compressive strength of cement stone, $\mathrm{MPa}$;

$\overline{P_{c e m}}-$ is an average market price of cement, c./t

б) lime

$$
T E_{l}^{f}=\frac{A}{\overline{C_{l}}}
$$

where $\mathrm{A}$ - is a lime activity, \%;

$\overline{\mathrm{C}_{\mathrm{l}}}-$ is an average market price of lime, c./t

B) coarse aggregate

$$
\mathrm{TE}_{\mathrm{a}}^{\mathrm{f}}=\frac{\mathrm{R}_{\mathrm{bi}}^{\mathrm{a}}}{\overline{\mathrm{C}_{\mathrm{al}}}}
$$

where $\mathrm{R}_{\mathrm{bi}}^{\mathrm{a}}$ - compressive strength of coarse aggregate, MPa;

$\overline{C_{a l}}-$ is an average market price of the i-th large aggregate, $\mathrm{c} . / \mathrm{m}^{3}$. 
Second approach to assess the technical and economic efficiency should be applied to the building materials and products for which several functional properties are priority. This provision is applied to the groups of structural, thermal insulation and finishing materials. So, for the structural and heat-insulating materials, the properties of strength and heatinsulating ability are important, and for finishing materials - the surface quality, durability, resistance to aggressive environmental influences, etc. [15]. For these nomenclature groups, it is proposed to assess the technical and economic efficiency according to the general scheme, reflecting both the diversity and the significance of properties for the consumer.

$$
\mathrm{TE}_{\mathrm{ij}}^{\mathrm{f}}=\frac{\sum_{\mathrm{g}=1}^{\mathrm{n}} \mathrm{k}_{\mathrm{gij}} \cdot \mathrm{a}_{\mathrm{gij}}}{\mathrm{P}_{\mathrm{ij}}}
$$

where $n-$ is the number of properties of the i-th building material included in the $\mathrm{j}$-th nomenclature group;

$\mathrm{k}_{\mathrm{gij}}$ - is a weight coefficient of the g-th property of the $\mathrm{i}$-th building material included in the $\mathrm{j}$-th nomenclature group, $0<\mathrm{k}_{\mathrm{gij}}<1$;

$\mathrm{a}_{\mathrm{gij}}-$ is the relative value of the g-th property of the $\mathrm{i}$-th building material included in the $\mathrm{j}$-th nomenclature group.

Wherein,

$$
a_{i j}=\frac{a_{i j}^{f}}{a_{i j}^{H}}
$$

where $\mathrm{a}_{\mathrm{ij}}^{\mathrm{f}}$ - is the actual value of the main property of the $\mathrm{i}$-th building material included in the $\mathrm{j}$-th nomenclature group, nat. unit.;

$\mathrm{a}_{\mathrm{ij}}^{\mathrm{min}}$ - is the lower normative limit of the main property of the $\mathrm{i}$-th building material included in the $\mathrm{j}$-th nomenclature group, nat. unit.

Separately, it should be noted that to determine the weighting factors of the functional properties of various building materials, it is advisable to rely on the method of expert assessments. In this case, special attention should be paid to the formulation of the task for the experts. In particular, in addition to providing a list of functional properties, it is imperative to indicate the operating conditions of the building material and provide a scale for assessing the properties' significance. Based on the results of the studies and calculations, it is recommended to use a scale from 1 to $g$, the value of which corresponds to the number of properties of the building material under consideration. In this case, the highest score is assigned to the most significant property. It is desirable that the values of the point marks are not repeated. The methodology for calculating the weighting factors of the functional properties of building materials and products is presented in detail in the sources $[16,17]$.

\section{Conclusion}

Assessment of technical and economic efficiency is fundamentally important when choosing building materials, products and structures at the design stage of buildings and structures for various purposes.

Within the framework of the architectural and construction system of the object, which unites a large number of products and structures, one group of structures perceives the acting loads and forms the structural system of the building, while others enclose the internal volume of the building, divides it into separate rooms, protect it from atmospheric influences, provide the required temperature, humidity, acoustic and other comfort modes. 
At the same time, the functionality of building products and structures in buildings does not necessarily turn out to be unambiguous, but more often it is multifaceted. So, in the buildings with load-bearing outer walls, the wall material combines the functions of a structural and heat-insulating material. In the case when a material with a finished front surface (for example, front brick) is used from the outside of the building, then the finishing material functions are added to the indicated functions. It is to take into account the shown functional versatility that the above-listed methodological approaches to assessing the technical and economic efficiency of the use of building materials, products and structures are proposed.

\section{References}

1. H. Leibenstein, The American Economic Review 56, 392-415 (1966)

2. O.S. Golubova, Socio-economic management: theory and practice 3, 7-10 (2019)

3. E.V. Korolev, A.S. Inozemtsev, S.S. Inozemtsev, Bulletin of the Volga State Technological University. Series: Materials. Constructions. Technologies 4, 8-18 (2019)

4. E.V. Korolev, Building materials 3, 85-89 (2017)

5. Yu.M. Bazhenov, E.V. Korolev, Building materials 6, 66-67 (2009)

6. E.V. Korolev, Vestnik MGSU 106, 711-717 (2017)

7. E.V. Korolev, Regional architecture and construction 3, 9-14 (2013)

8. V.B. Melekhin, T.G. Aygumov, A. Ya. Gamzatov, Construction Economics 2, 38-47 (2019)

9. N.V. Chepachenko, M.N. Yudenko, S.A. Nikolikhina, N.A. Polovnikova, Bulletin of civil engineers 6, 238-245 (2020)

10. D.N. Korotkikh, E.M. Chernyshov, Concrete technology 5 (6), $46-49$ (2019)

11. B.M. Kenzhin, T.M. Nurgozhin, Yu.M. Smirnov, M.A. Zhurunova, E.K. Construction: new technologies - new equipment 12, 50-53 (2018)

12. E.V. Smirnova, D.I. Vasyutkina, Bulletin of the Belgorod State Technological University named after V.G. Shukhov 1, 26-29 (2013)

13. P.V. Volkov, A.N. Tkachenko, Student and Science 1, 17-21 (2019)

14. S.F. Akimov, E. Sh. Akimova, Economics of construction and environmental management 4 5-16 (2018)

15. E.E. Katyashicheva, E.N. Petrov, Bulletin of Young Scientists of the St. Petersburg State University of Technology and Design 4, 85-93 (2020)

16. I.I. Akulova., G.S. Slavcheva, Housing construction 7, 9-12 (2017)

17. I. Akulova, G, Slavcheva, A new approach to identifying top-priority step for increasing the building materials competitiveness, IOP Conf. Series: Materials Science and Engineering (International science and technology conference "FarEastCon-2020") 1079032030 (2021) 